\title{
Various Light Quality including QD-LED Affect Growth and Leaf Color of Red Romaine Baby Leaf Lettuce
}

\author{
Su Jung $\mathrm{HAN}^{1}$, In-Lee $\mathrm{CHOI}^{1,2}$, Ju Young KIM ${ }^{1}$, Lixia WANG ${ }^{1}$, Joo H. LEE ${ }^{1}$, \\ $\mathrm{Ki}$-Young $\mathrm{CHOI}^{3}$, Young Wook $\mathrm{KOO}^{4}$, Yongduk $\mathrm{KIM}^{4}$, \\ Mohammad Z. ISLAM ${ }^{5}$, Young-Tack LEE ${ }^{5}$, Ho-Min KANG ${ }^{1,2 *}$
}

\author{
${ }^{1}$ Kangwon National University, Division of Horticulture and Systems Engineering, Program of Horticulture, Chuncheon 24341, \\ Korea; sujhans323@hanmail.net; cil1012@kangwon.ac.kr; aswndudsa@naver.com;13148310672@163.com; ot2581@naver.com; \\ hominkang@kangwon.ac.kr (*orrespondingauthor) \\ ${ }^{2}$ Kangwon National University, Agricultural and Life Science Research Institute, Chuncheon 24341, Korea \\ ${ }^{3}$ Kangwon National University, Department of Controlled Agriculture, Chuncheon 24341,Korea; choiky@kangwon.ac.kr \\ ${ }^{4}$ Cheorwon Plasma Research Institute, Cheorwon 24062, Korea; ywko@cpri.re.kr; ydkim@cpri.re.kr \\ ${ }^{5}$ Gachon University, Department of Food Science and Biotechnology, Seongnam 13120, Korea; zahirul@gachon.ac.kr; ytlee@gachon.ac.kr
}

\begin{abstract}
Light quality has a substantial effect on crops in plant factories. Quantum dot (QD) refers to ultrafine semiconductor particles and is expressed in a variety of wavelength ranges and fine and precise colors and is attracting attention as a nextgeneration material. This study was conducted to investigate the effects of various light qualities, including a QD-LED light source on the growth and color development of red romaine lettuce in the LED chamber system for plant factories. The light source was red fluorescent (FL), blue (B), red (R), blue + red mixed light (BR), and blue + wide range red + red mixed light QD-LED. The growth index, chlorophyll content, and leaf color were examined. The results showed that the plant length was long without a significant difference in QD-LED and the red (R) wavelength and showed the fastest growth under QD-LED. The photosynthetic rate and chlorophyll content were the highest in QD-LED light with a broad spectrum of red light. The leaf colors $\mathrm{a}^{*}, \mathrm{~b}^{*}$, the hue angle, and total anthocyanin content showed the highest in QD-LED light, while $\mathrm{b}^{*}$ and the hue angle values were the lowest. As the light wavelength range was changed, there was a significant difference in the growth response and leaf color, and it is considered that QD-LED light should be considered positively when applied to plant factories.
\end{abstract}

Keywords: anthocyanin; chlorophyll; hue angle; photosynthetic rate; plant factories

\section{Introduction}

The recent increase in the demand for convenient and healthy foods resulted in consumer interests in baby leaf vegetables, which are ready-to-eat (Santos et al., 2014). Baby leaf vegetables that have been in demand in recent years include lettuce, spinach, rocket, lamb's lettuce and Swiss chard (Fallove et al., 2009).

Lettuce has been widely used for research on baby leaf vegetables (Samuoliené et al., 2013; Jung, 2015) and hydroponics and environmental control research (Kang et al., 2016) because of its various shapes, colors and short growth period. In particular, lettuce has been used for research related to the light quality using artificial light sources in a closed plant factory environment due to the low light saturation point (Cha et al., 2013). The light quality of the artificial light in a closed plant factory has an important role on the quality and growth of crops (Lin et al., 2013). When lettuce was cultivated in various lights using a light emitting diode (LED), blue light influenced the growth of lettuce (Johkan et al., 2010), and the anthocyanin content of red leaf lettuce was affected, depending on the wavelength of the LED lights (Lee et al., 2010).

LED lights mainly used in existing studies on light quality are being used in plant factories; however, the high installation price, which results in a high early investment cost and high heat radiation of the LED lights, are problematic (Matsumoto et al., 2010). Recently, a quantum dot light source, which has a lower installation cost and 
758

power consumption compared to existing LED lights, has been introduced (Yoo et al., 2018). QD-LED (quantum dot-light emitting diode) lights have multiple wavelengths, high color purity, light stability, and high quantum efficiency characteristics, is based on color conversion used to convert the blue light from LED chips into different colors (Hang and Yang, 2017). These properties explain this light source's study and application in many areas (Hang and Yang, 2017).

However, research as a light source for plant cultivation is still insufficient. This study aimed to find the practical use of QD-LED light sources in plant factories using artificial light sources and basic data on producing high quality leafy vegetables by comparing the growth and quality of red romaine baby leaf lettuce under different light sources, which include QD-LED light sources.

\section{Materials and Methods}

\section{Plant materials and growth conditions}

Lettuce (Lactuca sativa L. 'Red Romaine') was sown in a plug tray (128 hole) containing a horticultural commercial substrate mix (Baroker, Seoul Bio, Korea) and was grown in a_climate chamber established with supplemental light equipment described below for 6 weeks. The air temperature was controlled to a $23 / 18^{\circ} \mathrm{C}$ day/night cycle; the relative humidity was $70 \%$, and the carbon dioxide concentration was ambient.

\section{Characteristics of light sources and light spectral analysis}

The light treatments consisted of an irradiance provided by cool white fluorescent lamp (5DULUX D FDX 18EXD, OSRAM, Korea), 10 W LED lights (Cheorwon Plasma Research Institute, Korea) with B (peak at $450 \mathrm{~nm}$ ), R (peak at $660 \mathrm{~nm}), \mathrm{B}+\mathrm{R}$ (peak at $450+660 \mathrm{~nm}$ ), and $10 \mathrm{~W}$ QD-
LED lights (Cheorwon Plasma Research Institute, Korea) with $\mathrm{B}+\mathrm{WR}+\mathrm{FR}$ (peak at 450 and $650 \sim 720 \mathrm{~nm}$ ). The lights were placed $15 \mathrm{~cm}$ above the plant canopy horizontally inside the climate chamber. The average $\mathrm{W}, \mathrm{B}$, $\mathrm{R}, \mathrm{B}+\mathrm{R}$ and $\mathrm{R}+\mathrm{WR}+\mathrm{PF}$ added by the supplemental light intensity (photosynthetic photon flux density) was 150 $\mu \mathrm{mol} \cdot \mathrm{m}^{-2} \cdot \mathrm{s}^{-1}$. The illumination of the main light sources and supplemental light sources was for $16 \mathrm{~h}$ per day in all of the treatments. The spectrum and intensity of the light sources used as treatments were measured using a spectroradiometer (HD2102.1, Delta OHM, Italy) and a quantum sensor (HD2102.1, Delta OHM, Italy) at the plant canopy levels (Fig. 1 and Table 1).

\section{Analysis of growth, colour, chlorophyll and anthocyanin}

Every 7 days after initiating supplemental light treatments ( 26 days after sowing), 10 plants were measured separately for measurements of plant growth, such as plant height, leaf length, and leaf width. Fresh weight, dry weight, leaf color, leaf chlorophyll concentration, and anthocyanin content were measured for five plants selected from each treatment at 6 weeks after the light treatments. The leaf chlorophyll concentration and leaf color were measured using SPAD (502Plus, Konica Minolta, Japan) and a colorimeter (CR-400, Knika Minolta, Japan), respectively. Total anthocyanin content was measured as described by Park et al. (2012). The $530 \mathrm{~nm}$ absorbance wavelength of a UV spectrophotometer (Shimadzu Corporation, Tokyo, Japan) was used. Each $2 \mathrm{~g}$ leaf sample was extracted after 24 $\mathrm{h}$ of $4{ }^{\circ} \mathrm{C}$ in the dark using $10 \mathrm{~mL}$ of $1.5 \mathrm{~N} \mathrm{HCl}-95 \%$ ethanol $(85: 15, \mathrm{v}: \mathrm{v})$. Total anthocyanin was calculated using the following formula:

Anthocyanin $(\mathrm{mg} / 100 \mathrm{~g}$ fresh wt. $)=($ absorbance at 530 $\mathrm{nm} x$ volume of extraction solution $\mathrm{x} 100) /($ wt. of sample of $\mathrm{gx}$ 98.2).
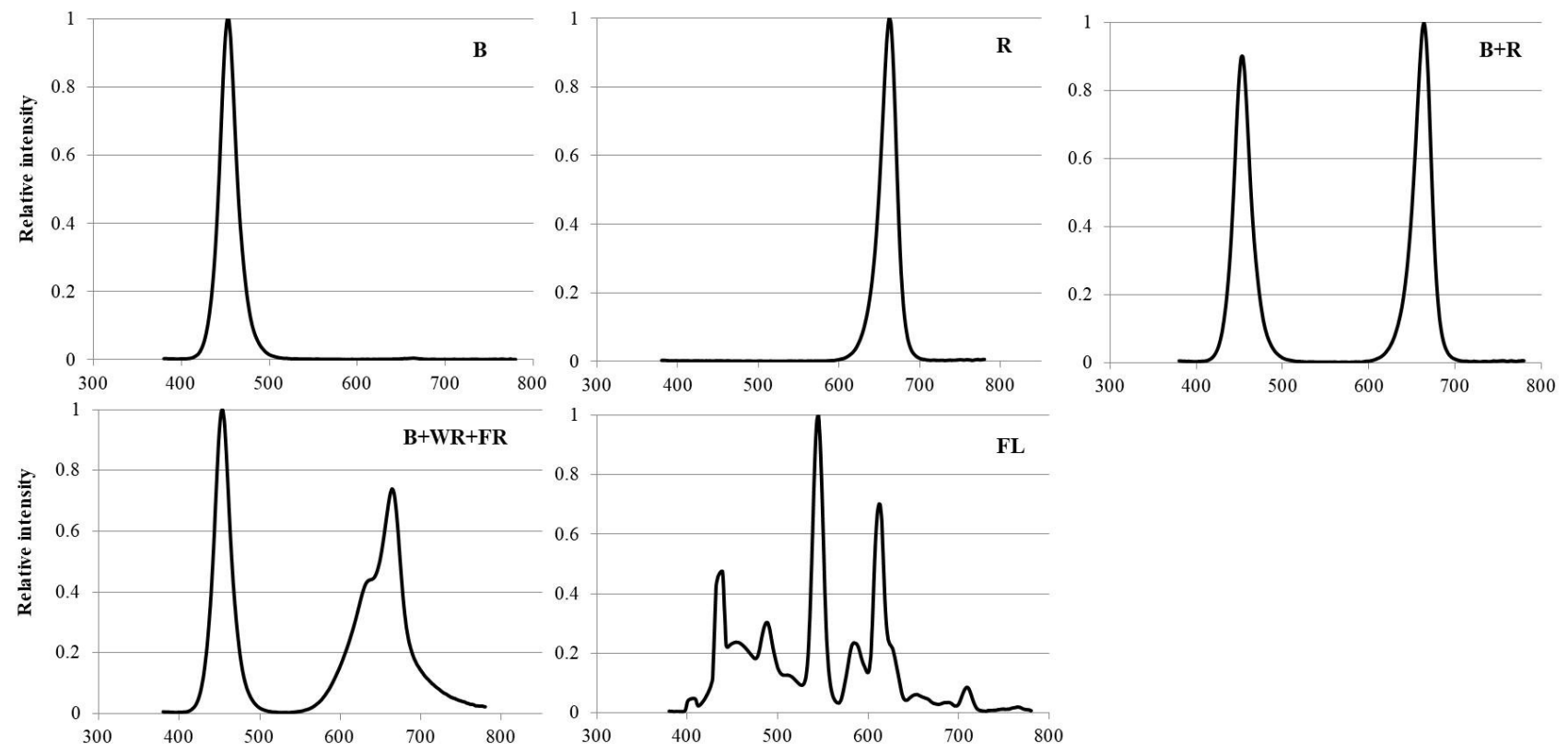

Fig. 1. Relative spectral distribution of the LEDs (B, R, B+R), QD-LED(B+WR+FR) and FL(cool white fluorescent lamp) used in this study. Photosynthetic photon flux was about $150 \mu \mathrm{mol} \cdot \mathrm{m}^{-2} \cdot \mathrm{s}^{-1}$ in each treatment. Spectral scans were recorded at the top of the pots and averaged at 5 points of each treatment 
Table 1. Spectrum wavelength ratio (\%) of light quality treatments measured on the growth bed bottom under $150 \mu \mathrm{mol} \cdot \mathrm{m}^{-2} \cdot \mathrm{s}^{-1}$ light intensity (Photosynthetic Photon Flux Density)

\begin{tabular}{|c|c|c|c|c|c|}
\hline \multirow{2}{*}{$\begin{array}{l}\text { Spectrum wavelength } \\
\text { Spectrum wavelength }\end{array}$} & \multicolumn{5}{|c|}{ Light quality treatments ${ }^{z}$} \\
\hline & FL & $\mathrm{B}$ & $\mathrm{R}$ & $\mathrm{B}+\mathrm{R}$ & $\mathrm{B}+\mathrm{WR}+\mathrm{FR}$ \\
\hline Blue (430-480 nm) & 22.3 & 93.3 & 0.3 & 44.0 & 34.6 \\
\hline Green $(520-570 \mathrm{~nm})$ & 26.5 & 0.2 & 0.1 & 0.2 & 0.6 \\
\hline Red 1(600-670 nm) & 23.4 & 0.3 & 82.3 & 41.9 & 41.0 \\
\hline $\operatorname{Red} 2(671-700 \mathrm{~nm})$ & 1.5 & 0.0 & 15.4 & 10.0 & 11.4 \\
\hline Far-red $(700-780 \mathrm{~nm})$ & 3.1 & 0.0 & 1.2 & 0.7 & 6.6 \\
\hline
\end{tabular}

${ }^{\mathrm{z}}$ Light quality treatments were a cool white fluorescent lamp, $10 \mathrm{~W}$ LED lights with B (peak at $\left.450 \mathrm{~nm}\right), \mathrm{R}$ (peak at $\left.660 \mathrm{~nm}\right), \mathrm{B}+\mathrm{R}($ peak at $450+660 \mathrm{~nm})$, and a $10 \mathrm{~W}$ QD-LED light with B+WR+FR (peak at 450 and $650 \sim 720 \mathrm{~nm}$ ).

\section{Measurement of photosynthetic rate, transpiration and stomatal conductance}

At 25 days after sowing, the photosynthetic rate, transpiration and stomatal conductance were measured from five typical fully expanded canopy leaves per light treatment using a portable photosynthetic meter (model LI6400xt, LI-COR Inc., USA) and steady state porometer (model LI-1600, LI-COR), respectively. The conditions of measurements were $150 \mu \mathrm{mol} \cdot \mathrm{m}^{-2} \cdot \mathrm{s}^{-1}$ light intensity, $22.5^{\circ} \mathrm{C}$ leaf temperature, $400 \mu \mathrm{mol} \cdot \mathrm{m}^{-2}$ of carbon dioxide concentration, and $500.5 \mu \mathrm{mol} \cdot \mathrm{s}^{-1}$ flow rate, and RH 55\%.

\section{Statistical analysis}

Statistical analyses were performed using SPSS (IBM SPSS Statistics version 22, SPSS Inc., Chicago, IL) statistical program. Duncan's one-way ANOVA was used to analyse the significance according to light quality treatments at significance level 0.05 . The mean separations were conducted using Microsoft Excel 2010 (Microsoft Co., USA).

\section{Results and Discussion}

\section{Growth characteristics}

The growth of red romaine based on the light quality was different depending on growth factors, such as plant height, leaf length and leaf width. The plant height was longer in the red light (R) and QD-LED light $(\mathrm{B}+\mathrm{WR}+\mathrm{FR})$ and shorter in the blue light (B) and fluorescent light $(\mathrm{FL})$ treatments during the light treatment period. The leaf length and leaf width were higher in the order of the QD-LED light $(\mathrm{B}+\mathrm{WR}+\mathrm{FR})$ and mixed light $(\mathrm{B}+\mathrm{R})$, and fluorescent light $(\mathrm{FL})$, which had the shortest leaf length, at 36\% of QDLED light and red light $(\mathrm{R})$, with the narrowest leaf width using only $27 \%$ of the QD-LED light. Li and Kubota (2009) also reported that far-red light promotes the growth of the leaves and leaf width, and QDLED light containing far-infrared light has the best growth.

The growth of the upper part of the lettuce is promoted by the red light $(\mathrm{R})$, and the blue light (B) suppressed growth (Lee et al., 2010). In addition, it is more efficient to promote photosynthesis by irradiating red light and blue or far-red lights for growth, rather than using a single wavelength light (Ouzounis et al., 2015).

The leaf shape was measured to investigate the effect of the light source on the morphological development of red romaine lettuce. However, in the late stage of growth, red leaf $(\mathrm{R})$ promoted only the leaf length and showed a much higher leaf shape index (Fig. 3). It has been reported that the plant length of the 'Lollo rosa' lettuce was longer in the red light condition (Shin et al., 2012), and the light quality has been reported to act not only as an energy source for plant growth, morphogenesis, and pigmentation but also as a regulator (Fankhauser and Chory, 1997). The shoot fresh weight at the end of cultivation was the heaviest in the QDLED light treatment and mixed light $(B+R)$ followed by red light (R), blue light (B) and fluorescent light (FL). In addition, the shoot dry matter ratio was the highest in QDLED light, and there was no significant difference among the other light sources (Table 2).

Table 2. Top fresh weight, top dry matter ratio, photosynthetic rate, stomatal conductance, and transpiration rate of red romaine grown in each light quality treatment

\begin{tabular}{cccccc}
\hline $\begin{array}{c}\text { Light quality } \\
\text { treatments }^{2}\end{array}$ & $\begin{array}{c}\text { Top Fresh weight } \\
(\mathrm{g})\end{array}$ & $\begin{array}{c}\text { Top dry mater } \\
\text { ratio }(\%)\end{array}$ & $\begin{array}{c}\text { Photosynthetic rate } \\
\left(\mu \mathrm{mol} \cdot \mathrm{CO}_{2} \cdot \mathrm{m}^{-2} \cdot \mathrm{s}^{-1}\right)\end{array}$ & $\begin{array}{c}\text { Stomatal conductance } \\
\left(\mathrm{mol} \cdot \mathrm{H}_{2} \mathrm{O} \cdot \mathrm{m}^{-2} \cdot \mathrm{s}^{-1}\right)\end{array}$ & $\begin{array}{c}\text { Transpiration rate } \\
\left(\mathrm{mol} \cdot \mathrm{H}_{2} \mathrm{O} \cdot \mathrm{m}^{-2} \cdot \mathrm{s}^{-1}\right)\end{array}$ \\
\hline FL & $0.53 \mathrm{~b}^{y}$ & $4.61 \mathrm{~b}$ & $3.17 \mathrm{~d}$ & $0.06 \mathrm{a}$ & $1.72 \mathrm{ab}$ \\
$\mathrm{B}$ & $0.67 \mathrm{~b}$ & $4.91 \mathrm{~b}$ & $4.96 \mathrm{bc}$ & $0.07 \mathrm{a}$ & $1.78 \mathrm{ab}$ \\
$\mathrm{R}$ & $0.76 \mathrm{~b}$ & $3.35 \mathrm{~b}$ & $3.81 \mathrm{~cd}$ & $0.04 \mathrm{a}$ & $1.18 \mathrm{~b}$ \\
$\mathrm{~B}+\mathrm{R}$ & $1.10 \mathrm{a}$ & $5.39 \mathrm{~b}$ & $6.12 \mathrm{~b}$ & $0.07 \mathrm{a}$ & $2.02 \mathrm{ab}$ \\
$\mathrm{B}+\mathrm{WR}+\mathrm{FR}$ & $1.19 \mathrm{a}$ & $8.31 \mathrm{a}$ & $7.35 \mathrm{a}$ & $0.08 \mathrm{a}$ & $2.56 \mathrm{a}$ \\
\hline
\end{tabular}

${ }^{\overline{2}}$ Light quality treatments were a cool white fluorescent lamp, $10 \mathrm{~W}$ LED lights with B (peak at $450 \mathrm{~nm}$ ), R (peak at $\left.660 \mathrm{~nm}\right), \mathrm{B}+\mathrm{R}$ (peak at $\left.450+660 \mathrm{~nm}\right)$, and a $10 \mathrm{~W}$ QD-LED light with B+WR+FR (peak at 450 and $650 \sim 720 \mathrm{~nm}$ ).

${ }^{\mathrm{y}}$ Mean separation of columns by Duncan's multiple range tests at $\mathrm{p} \leq 0.05$. 

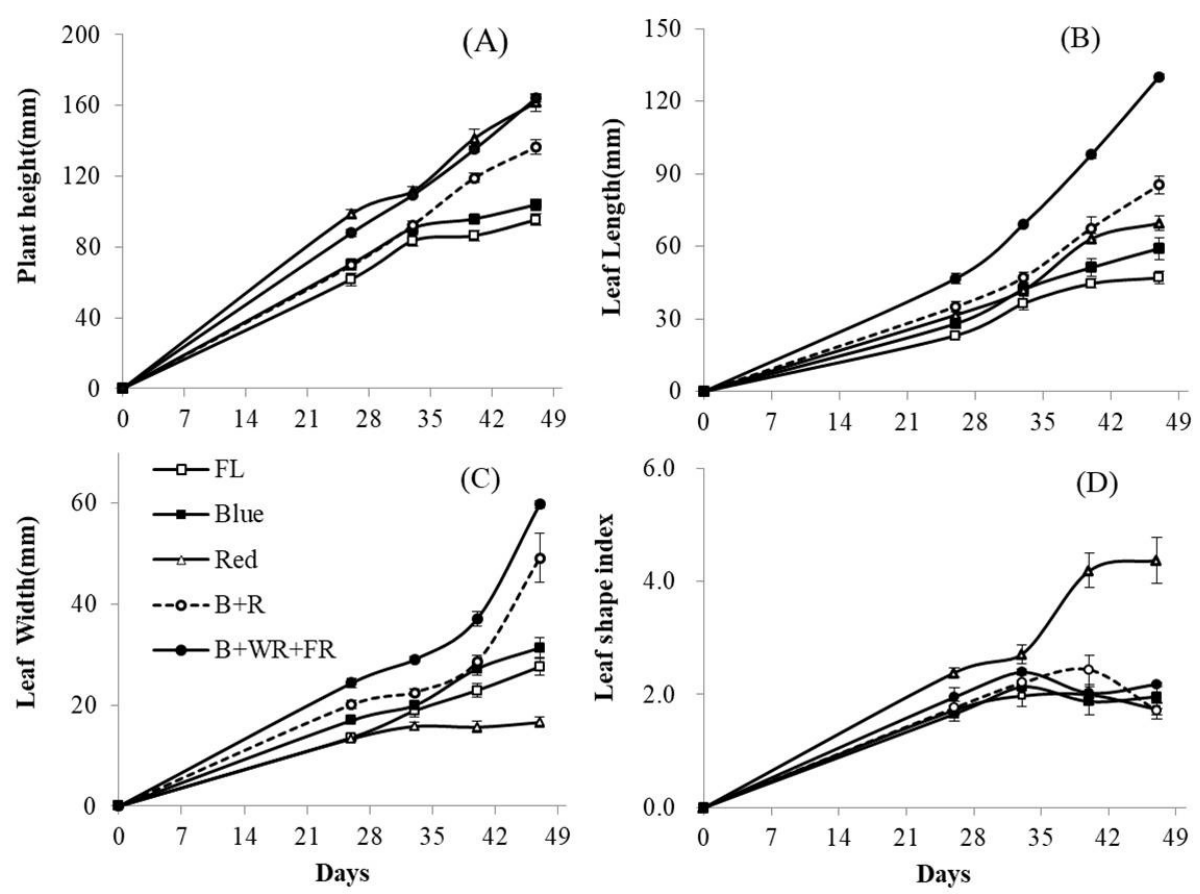

Fig. 2. Change of plant height(A), leaf length(B), leaf width(C), and Leaf shape(D) of red romaine grown in each light quality treatments which were a cool white fluorescent lamp, $10 \mathrm{~W}$ LED lights with B (peak at $450 \mathrm{~nm}$ ), R (peak at $660 \mathrm{~nm}$ ), B+R (peak at $450+660 \mathrm{~nm}$ ), and a $10 \mathrm{~W}$ QD-LED light with $\mathrm{B}+\mathrm{WR}+\mathrm{FR}$ (peak at 450 and $650 \sim 720 \mathrm{~nm}$ ). The data represent the means and the vertical bars indicate standard errors $(\mathrm{n}=10)$

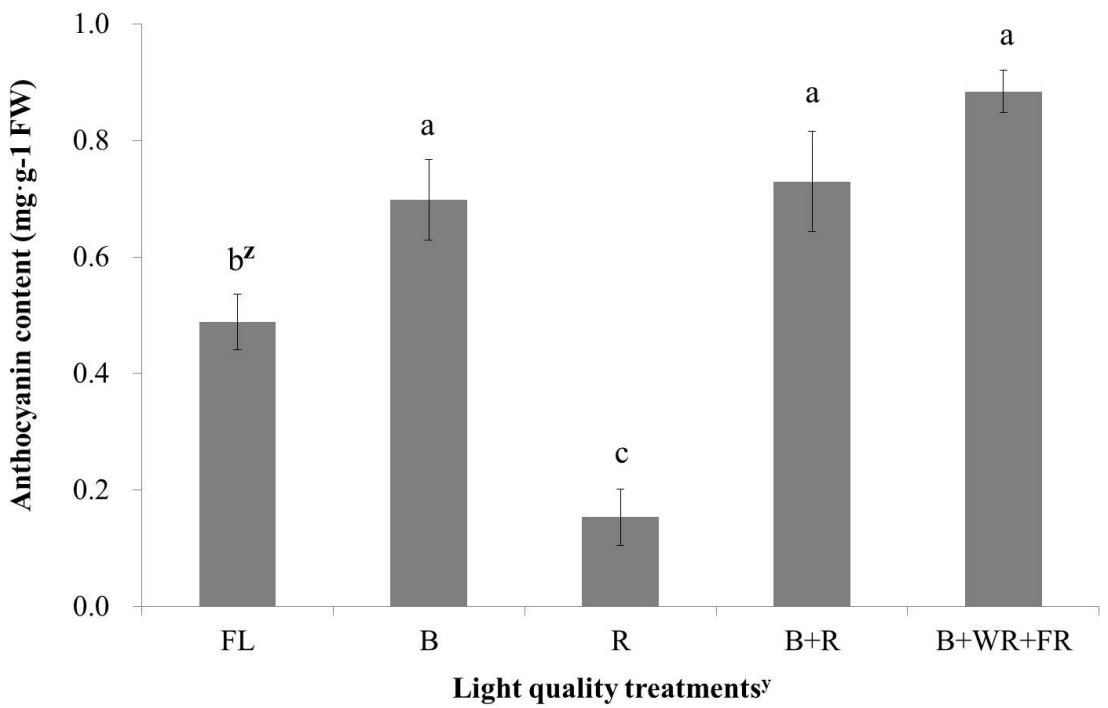

Fig. 3. Total anthocyanin content of red romaine grown in each light quality treatments. The data represent the means and the vertical bars indicate standard errors $(n=5) .{ }^{z}$ Mean separation of treatments by Duncan's multiple range tests at $p \leq 0.05 .{ }^{y}$ Light quality treatments were a cool white fluorescent lamp, $10 \mathrm{~W}$ LED lights with B (peak at $450 \mathrm{~nm}$ ), R (peak at $660 \mathrm{~nm}$ ), B+R (peak at $450+660 \mathrm{~nm}$ ), and a $10 \mathrm{~W}$ QD-LED light with B+WR+FR (peak at 450 and $650 \sim 720 \mathrm{~nm}$ )

Comparison of photosynthetic rate, transpiration and stomatal conductance

The photosynthetic rate at 25 days after sowing was the highest in the QD-LED light and the lowest in the fluorescent light (FL) and red light (R). The transpiration rate was the highest in the QD-LED and the lowest in red light (R). However, the stomatal conductance did not show any statistical significance among the treatments (Table 2).

The photosynthetic rate of plants is affected by the light quality, but the mixed light sources of these were much higher than the red or blue monochromatic light (Matsuda et al., 2007; Savvides et al., 2012).

In addition, the highest photosynthetic rate is observed with the QD-LED light because the QD-LED light simultaneously irradiated blue and red, which are effective for photosynthesis and red external light and can expect an Emerson enhancement effect (Govindjee and Govindjee, 1964). In addition, Li and Kubota (2009) reported that far- 
red was effective at increasing the growth of lettuce. In this experiment, the final growth index of the QD-LED light was the highest, and the photosynthetic rate was also significantly higher.

\section{Color and phytochemical contents}

The chlorophyll content (SPAD) was the highest in the QD-LED light at the end of cultivation and the lowest in the fluorescent light (FL) and red light (R) (Table 3). Wongnok et al. (2008) reported that the light quality affects the chlorophyll content of lettuce and that the blue light is related to the chlorophyll accumulation in the leaves. The higher the ratio of the blue light is, the higher the chlorophyll content is (Hogewoning et al., 2010; Johkan et al., 2010). In this experiment, the chlorophyll content was low in fluorescent light (FL) and red light (R), which have a relatively low proportion of blue light, and showed similar results as the previous study.

The $\mathrm{a}^{*}$ value of the leaf, which indicates the red colour as the value increases in green, was the highest in the QD-LED light and the lowest in the red light (R), and the $b^{*}$ value indicating blue to yellow was the highest in the red light $(\mathrm{R})$ and the lowest in the QD-LED light. In addition, the hue angle value was the lowest in the QD-LED light (Table 3). The anthocyanin content of red romaine was reported to increase with lower hue angle and higher SPAD (Gazula $e t$ al., 2007; Lee and Kim, 2014). In this experiment, total anthocyanin content was significantly higher in the QDLED light, which had a lower hue angle and a higher SPAD value than other treatments. Alternatively, it was lowest in the red light $(\mathrm{R})$ and was more than 5 times larger in the QD-LED light. Nishimura et al. (2006) reported that the anthocyanin content is increased when two light sources of red light and blue light are mixed. In this experiment, it was higher in the QD-LED light and the $(B+R)$ mixed light that were mixed with blue and red light. Therefore, it was determined that the QD-LED light is more effective for the red coloration of red romaine lettuce than for the other light sources, and Lee et al. (2010) reported that the growth of the lettuce and the content of the pigment could be controlled simultaneously based on the light quality of the LED light source. As described above, there was a significant difference in the growth and leaf colour of the red romaine baby leaf lettuce based on the change of the light wavelength, and the growth and red colouring were effective in the mixed light source of the red wavelength with the near infrared wavelength and the blue (B) light source. Therefore, the QD-LED light with a mixed wavelength band shows promise for application in plant factories to produce baby leafy vegetables.

Table 3. Chlorophyll and Leaf color (Hunter $\mathrm{a}^{*}, \mathrm{~b}^{*}$, and hue angle) of red romaine grown in each light quality treatment

\begin{tabular}{|c|c|c|c|c|}
\hline \multirow{2}{*}{ Light quality treatments ${ }^{2}$} & \multirow{2}{*}{$\begin{array}{l}\text { Chlorophyll } \\
\text { (SPAD) }\end{array}$} & \multicolumn{3}{|c|}{ Leaf color(value) } \\
\hline & & Hue angle & $a^{*}$ & $\mathrm{~b}^{*}$ \\
\hline FL & $19.26 c^{y}$ & $125.07 \mathrm{a}$ & $-10.889 b$ & $15.084 \mathrm{~b}$ \\
\hline B & $22.06 \mathrm{bc}$ & $122.48 \mathrm{a}$ & $-8.481 b$ & $12.907 \mathrm{~b}$ \\
\hline $\mathrm{R}$ & $21.28 \mathrm{c}$ & $127.93 \mathrm{a}$ & $-18.079 c$ & $23.237 \mathrm{a}$ \\
\hline $\mathrm{B}+\mathrm{R}$ & $25.64 \mathrm{ab}$ & $123.98 \mathrm{a}$ & $-8.556 b$ & $12.358 \mathrm{~b}$ \\
\hline $\mathrm{B}+\mathrm{WR}+\mathrm{FR}$ & $28.34 \mathrm{a}$ & $109.00 \mathrm{~b}$ & $-3.841 \mathrm{a}$ & $8.259 c$ \\
\hline
\end{tabular}

\section{Acknowledgements}

This work was supported by Korea Institute of Planning and Evaluation for Technology in Food, Agriculture, and Forestry (IPET) through Advanced Production Technology Development Program, funded by Ministry of Agriculture, Food and Rural Affairs (MAFRA) (11611103).

\section{References}

Cha MK, Cho JH, Cho YY (2013). Growth of leaf lettuce as affected by light quality of LED in closed-type plant factory system. Protected Horticulture and Plant Factory 22:291-297.

Fallove C, Rouphael Y, Rea E, Battistelli A, Colla G (2009). Nutrient solution concentration and growing season affect yield and quality of Lactuca sativa L. var. acephala in floating raft culture. Journal of the Science of Food Agriculture 89(10):1682-1689.
Fankhauser C, ChoryJ (1997). Light control of plant development. Annual Review ofCell and Developmental Biology 13(1):203-229.

Gazula A, Kleinhenz MD, Scheerens JC (2007). Anthocyanin levels in nine lettuce (Lactuca sativa) cultivars: Influence of planting date and relations among analytic, instrumented, and visual assessments of color. HortScience 42(2):232-238.

Govindjee R, Govindjee GH (1964). Emerson enhancement effect in chloroplast reactions. Plant Physiology 39(1):10-14.

Han CY, Yang H (2017). Development of colloidal quantum dots for electrically driven light-emitting devices. Journal of the Korean Ceramic Society $54(6): 449-469$.

Hogewoning SW, Trouwborst G, Maljaars H, Poorter H, van Leperen W, Harbinson J (2010). Blue light dose responses of leaf photosynthesis, morphology, and chemical composition of Cucumis sativus grown under different combinations of red and blue light. Journal of Experimental Botany 61(11):3107-3117. 
762

Johkan M, Shoji K, Goto F, Hashida S, Yoshihara T (2010). Blue lightemitting diode light irradiation of seedlings improves seedling quality and growth after transplanting in red leaf lettuce. HortScience 45(12):1809-1814.

Jung MJ (2015). The determination of suitable MAP condition and postharvest pretreatments for several baby leaf vegetables. Thesis of master's degree, Kangwon National University, Chuncheon, Korea, pp 3.

Kang WH,Zhang F, Lee JW, Son JE (2016). Improvement of canopy light distribution, photosynthesis, and growth of lettuce (Lactuca sativa L.) in plant factory conditions by using filters to diffuse light from LEDs. Korean Journal of Horticultural Science and Technology 34(1):84-93.

Lee JG, Oh SS, ChaSH, Jang YA (2010). Effects of red/blue light ratio and short-term light quality conversion on growth and anthocyanin contents of baby leaf lettuce. Journal of Bio-Environmental Control 19:351-359.

Lee JS, Kim YH (2014). Growth and anthocyanins of lettuce grown under red or blue light-emitting diodes with distinct peak wavelength. Korean Journal of Horticultural Science and Technology 32(3):330-339.

Li Q, Kubota C (2009). Effects of supplemental light quality on growth and phytochemicals of baby leaf lettuce. Environmental and Experimental Botany 67(1):59-64.

Lin KH, Huang MY, Huang WD, Hsu MH, Yang ZW, Yang CM (2013). The effects of red, blue, and white light-emitting diodes on the growth, development, and edible quality of hydroponically grown lettuce (Lactuca sativa L.var.capitata). Scientia Horticulturae 150:86-91.

Matsuda R, Ohashi-KanekoK, Fujiwara K, Kurata K(2007). Analysis of the relationship between blue-light photon flux density and the photosynthetic properties of spinach (Spinacia oleracea L.) leaves with regard to the acclimation of photosynthesis to growth irradiance. Soil Science and Plant Nutrition 53(4):459-465.

Matsumoto T, Ihoh H, Shirai Y, Uno Y (2010). Effects of light quality on growth and nitrate concentration in lettuce. Journal of Shita 22(3):140147.
Nishimura T,Zobayed SMA, Kozai T, Goto E(2006). Effect of light quality of blue and red fluorescent lamps growth of St. John's wort (Hypericum perforatum L.). Journal of Society of High Technology in Agriculture. http://agris.fao.org/agris-search/search.do?recordID=JP2007001116.

Ouzounis T, Rosenqvist E,Ottosen C (2015). Spectral effects of artificial light on plant physiology and secondary metabolism: a review. Horticultural Science 50(8):1128-1135.

ParkJE, Park YG, Jeong BR, Hwang SJ (2012). Growth of lettuce in closedtype plant production system as affected by light intensity and photoperiod under influence of white LED light. Protected Horticulture and Plant Factory 22:228-233.

Samuolienė G, Brazaitytè A, Sirtautas R, Viršie A, Sakalauskaite J, Sakalauskiene S, Duchovskis S (2013). LED illumination affects bioactive compounds in romaine baby leaflettuce. Journal of the Science of Food and Agriculture 93(13):3286-3291.

Santos J, Oliveira MBPP, Ibanez E, Herrero M (2014). Phenolic profile evolution of different ready-to-eat baby-leaf vegetables during storage. Journal ofChromatography A 1327:118-131.

Savvides A, Fanourakis D, van Leperen W (2012). Coordination of hydraulic and stomatal conductance across light qualities in cucumber leaves. Journal of Experimental Botany 63:1135-1143.

Shin YS, Lee MJ, Lee ES, Ahn JH, Lim JH, Kim HJ, ... Chai JH (2012). Effect of LEDs (Light Emitting Diodes) irradiation on growth and mineral absorption of lettuce (Lactuca sativa L. 'Lollo Rosa'). Journal of Bio-Environmental Control 21(3):180-185.

Wongnok A, Piluek C, Tantivivat S (2008). Effects of light emitting diodes on micropropagation of Phalaenopsis orchids. Acta Horticulturae 788:149-156.

Yoo YW, Ko YW, Kim YD, Shin JC, Park TH, Oh ST, ... Kim MK (2018). High efficiency QD lighting for plant growth. KIIEE Spring Conference, pp 86. 